LIAMES, Campinas, SP, v. 20, 1-27, e020012, 2020

\title{
Incorporação nominal e aspecto lexical em Tenetehára (Tupí-Guaraní) $^{1}$
}

\author{
Ricardo Campos Castro ${ }^{2}$ \\ Universidade Estadual de Campinas / FAPESP, Brasil \\ https://orcid.org/0000-0003-3513-1409
}

\begin{abstract}
This paper aims to investigate the mechanism of Noun Incorporation in the Tenetehára language and its relationship with the aspectual classes proposed by Vendler (1967). In that language, the Noun Incorporation mechanism occurs through two different morphosyntactic contexts: (i) total incorporation of the object into $\mathrm{v}^{0}$ and (ii) incorporation of the genitive phrase head into the $\mathrm{v}^{\circ}$. In total incorporation, when the direct object is incorporated into the verbal predicate, a predicate that behaves like an intransitive verb is generated. However, in possessor stranding constructions, only part of the genitive phrase, namely its heads, can be incorporated into the head of the vP. The result of this process does not change the initial transitive structure. Thus, in possessor stranding constructions there is no decrease in valence, despite the Noun Incorporation. Furthermore, in relation to the semantic plane of this constructions, what I have observed is that speakers of that language tend to point out two distinct interpretations, one for the version without Noun Incorporation and another interpretation for the version with Noun Incorporation. Thus, in this article, I intend to answer which constant organization can be inferred from the presented interpretation paradigm. The hypothesis regarding the differences in interpretation between these specific data has to do with the notion of verbal aspect and the definitions of accomplishment and achievement outlined by Vendler (1967). In this sense, my hypothesis is that constructions without Noun Incorporation can conform to the semantic class of verbal predicates of accomplishment, whereas versions with Nominal Incorporation in possessor stranding contexts obligatorily include achievement predicates.

KEYWORDS: Tupí-Guaraní; Tenetehára; Noun incorporation; Possessor stranding; Semantics.
\end{abstract}

RESUMO: Este trabalho tem por objetivo investigar o mecanismo de Incorporação Nominal na língua Tenetehára e sua relação com as classes aspectuais propostas por Vendler (1967). Nessa língua, o mecanismo de Incorporação Nominal se realiza por meio de dois diferentes contextos morfossintáticos: (i) incorporação total do objeto ao $v^{o}$ e (ii) incorporação do núcleo do sintagma genitivo ao $v^{o}$. Na incorporação total, quando

${ }^{1}$ Eu gostaria de registrar meus agradecimentos a dois pareceristas anônimos da Revista LIAMES: Linguas Indígenas Americanas, cujas críticas contribuíram para o aperfeiçoamento deste trabalho. Esta investigação foi desenvolvida durante trabalhos a campo realizados nas seguintes Terras Indígenas: Araribóia (aldeias Lagoa Quieta, Juçaral, Barreirinha e Zutiwa), Bacurizinho (aldeia Bacurizinho) e Caru (aldeia Maçaranduba) entre os anos 2010 e 2019. Eu agradeço também ao povo indígena Tenetehára por seu importante apoio, sem o qual não seria possível realizar a pesquisa aqui apresentada; em especial à Cíntia Maria Santana da Silva Guajajára, Pedro Paulino Guajajára e Raimundo Alves de Lima Guajajára. Os erros e as inconsistências que persistem são de minha inteira responsabilidade.

${ }^{2}$ Professor visitante (pós-doutorado) no Instituto de Estudos da Linguagem (IEL) da Universidade Estadual de Campinas (UnICAMP). Esta pesquisa conta com o apoio financeiro da Fundação de Amparo à Pesquisa do Estado de São Paulo (FAPESP). Processo 2017/09615-9. E-mail para contato: ricardorrico@uol.com.br.

DOI: http://dx.doi.org/10.20396/liames.v20i0.8659153 


\section{CASTRO - INCORPORAÇÃO NOMINAL E ASPECTO LEXICAL...}

o objeto direto se incorpora ao predicado verbal, é gerado um predicado que se comporta como um verbo intransitivo. Todavia, nas construções de alçamento do possuidor, apenas parte do sintagma genitivo, a saber seu núcleo, pode se incorporar ao núcleo do $v \mathrm{P}$. O resultado desse processo não altera a estrutura transitiva inicial. Assim, nas construções de alçamento do possuidor não ocorre diminuição de valência, apesar de haver Incorporação Nominal. Ademais, em relação ao plano semântico das construções de alçamento de objeto, o que tenho observado é que os falantes dessa língua costumam apontar duas interpretações distintas, uma para a versão sem Incorporação Nominal outra para a versão com Incorporação Nominal. Assim, no presente artigo, pretendo responder qual organização constante se pode depreender do paradigma de interpretação apresentado. A hipótese que defenderei é que as nuances de sentido entre estes dados têm a ver com a noção de aspecto verbal e as definições de accomplishment e achievement delineadas por Vendler (1967). Neste sentido, minha hipótese é de que as construções sem Incorporação Nominal podem se conformar à classe semântica de predicados verbais de accomplishment, ao passo que as versões com Incorporação Nominal em contextos de alçamento de objeto abrangem obrigatoriamente os predicados de achievement.

Palavras-chave: Tupí-Guaraní; Tenetehára; Incorporação nominal; Alçamento de possuidores; Semântica.

\section{Introdução}

O presente artigo pretende investigar como o mecanismo da Incorporação Nominal, doravante IN, na língua Tenetehára (Ramo IV, Família linguística Tupí-Guaraní, Tronco Tupí), ${ }^{3}$ relaciona-se com as classes aspectuais de Vendler (1967).

Conforme Mithun (1984: 848), "o termo incorporação é geralmente utilizado para se referir a um tipo particular de composição em que um V[erbo] e um N[ome] se combinam para formar um novo V[erbo]" ${ }^{4}$ Com o objetivo de fornecer uma exemplificação inicial, apresento os dados em (1) da língua chilena Mapudungun: ${ }^{5}$

$\begin{array}{clllll}\text { (1a) ñi chao } & \text { kintu-le-y } & \text { ta.chi } & p u & \text { waka } \\ \text { meu pai olhar-PROG-IND.3ss } & \text { a } & \text { COLL } & \text { vaca } \\ \text { 'Meu pai está olhando para as vacas' } & & & \end{array}$
(1b) ñi chao kintu-waka-le-y
meu pai olhar-vaca-PROG-IND.3ss
'Meu pai está olhando para as vacas'

(Salas 1992: 195)

Veja que em (1a), o predicado verbal transitivo kintu 'olhar' seleciona dois argumentos nucleares, a saber: o sujeito ñi chao 'meu pai' e o objeto ta.chi pu waka 'as vacas'. Em (1b), por sua vez, há um processo morfossintático de incorporação do núcleo do objeto waka 'vacas'; formando-se o predicado kintu-waka-le-y 'olhar para as vacas', uma configuração sintática cuja natureza é equivalente a uma estrutura intransitiva. Isto porque o núcleo do objeto se desloca de sua posição de base, incorporando-se à raiz verbal a partir de uma posição argumental.

${ }^{3}$ A seção 6 é devotada a questões relacionadas à autodenominação, localização geográfica e filiação linguística deste povo e língua.

${ }^{4}$ The term 'incorporation' is generally used to refer to a particular type of compounding in which a $\mathrm{V}$ and N combine to form e new V" (Mithun 1984: 848).

${ }^{5}$ A língua Mapuche ou Mapudungun é o idioma dos mapuches, um povo ameríndio que habita regiões do Chile e da Argentina. A língua é falada por cerca de 440.000 falantes com muitos graus de competência linguística. 
Em conformidade com Baker $(1988,1995,1996)$ e Baker et al. (2005), a IN é um fenômeno sintático, em que um núcleo é movido de sua posição de base para uma posição mais alta. Dessa maneira, o autor postula que a incorporação é o movimento de um núcleo para outro núcleo, uma instância generalizada de mover $\alpha \cdot{ }^{6}$ Tal movimento deve satisfazer o Princípio da Categoria Vazia (Empty Category Principle - ECP). ${ }^{7}$

Assim, o elemento deslocado precisa deixar um vestígio na posição sintática em que é gerado. Esse vestígio deve ser c-comandado pelo objeto movido. Além disso, de acordo com Baker (1988), na operação sintática de IN, deve haver uma relação biunívoca entre a estrutura semântica e a estrutura sintática. Isso significa que a Hipótese da Uniformidade de Atribuição Theta (Uniformity of Theta-Assignment Hyphotesis - UTAH) ${ }^{8}$ deve ser satisfeita. Assim sendo, quando os itens são inseridos na derivação, deve haver um mapeamento biunívoco, a saber: a relação entre a estrutura temática e a estrutura sintática deve ser preservada.

A seguir, apresento ${ }^{9}$ outra paráfrase temática em que o fenômeno sintático da IN fica bem assentado. Os dados são da língua Chukchi. ${ }^{10}$

$\begin{array}{lll}\text { (2a) } i{ }^{\prime} i \quad y e-k-h r e k-s & n e & \text { yao-kar-? } \\ \text { eu TL-1Ss-empurar-PERF } & \text { DET } & \text { PRE-barco-SUF } \\ \text { 'Eu empurrei o barco' } & & \end{array}$

(2b) i'i ye-k-kar-hrek-s

eu TL-1Ss-barco-empurrar-PERF

'Eu empurrei o barco'
(Postal 1962)

(Postal 1962)

Conforme mostra o exemplo (2a), o predicado transitivo hrek 'empurrar' seleciona o sujeito de primeira pessoa i' $i$ e o objeto kar 'barco'. Por sua vez, em (2b), há um processo de incorporação do núcleo do objeto kar 'barco'. Ao final desse processo, forma-se uma configuração sintática cuja natureza é equivalente a uma estrutura intransitiva, visto que o núcleo do objeto se move para a posição de núcleo da raiz verbal a partir de uma posição argumental. Neste sentido, o resultado é a presença de apenas um argumento na estrutura

${ }^{6}$ De acordo com Chomsky (1981), mova $\alpha$ associa duas representações estruturais. Segundo esta regra, é possível mover qualquer categoria para qualquer posição, deixando um vestígio na posição inicial. O movimento é, no entanto, restringido por princípios gerais da gramática.

${ }^{7}$ Consoante Baker (1988), "The ECP states in essence that every empty category, and in particular the trace left by wh-movement, must be governed either by something that assigns it a theta role, or by its antecedent" (Baker 1988: 364).

${ }^{8}$ Conforme Baker (1988), a UTAH é definida da seguinte forma: "Identical thematic relationships between items are represented by identical structural relationships between those items at the level of D-structure" (Baker 1988: 364).

${ }^{9}$ Abreviaturas utilizadas neste trabalho: 1, 2, 3: primeira, segunda e terceira pessoas; I: SÉRIE I; ABS: Caso Absolutivo; CORR: prefixo correferencial e de terceira pessoa $\{w-\sim o-\sim u$ - $\}$; DET: deteminante; DIM: diminutivo; ENF: ênfase; ERG: caso ergativo; FOC: foco; G: genérico; O: objeto; NOML: nominalizador; PERF: perfectivo; PRE: prefixo; PL: plural; PO: pronome objetivo; POSS: possessivo/genitivo; R: prefixo relacional; REFER: referenciante; SG: singular; s: sujeito; Ss: sujeito singular; SUF: sufixo; TL: translocativo.

${ }^{10}$ A Língua Chukoto ou Chukchi é uma das Línguas paleo-siberianas faladas pelos Chukchis no ponto mais extremo da Sibéria, em especial no Okrug Autônomo Chukotka. 
sintática superficial. Este fenômeno fica instanciado por meio da configuração sintática a seguir:

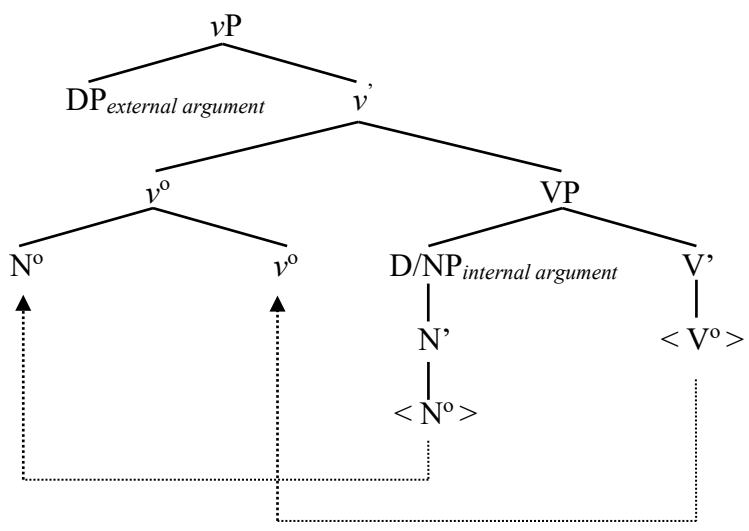

Note agora uma situação na qual apesar de haver incorporação de um núcleo a um predicado verbal transitivo, este mantém sua valência inalterada, como no dado abaixo da mesma língua do exemplo anterior.

\section{(4a) ənan remkal?-in pojg-ən macatku-nin}

3PL.ERG convidado-POss lança-ABS quebrar-3sG.S/3sG.o

'Ele quebrou a lança do convidado'

(4b) дnan pojg $2=$ mcatko-nen

3PL.ERG lança=quebrar-3sG.S/3sG.o convidado-ABS

'Ele quebrou a lança do convidado' remkal?-an

(Spencer 1995: 450)

Pode-se observar que, em (4a), o predicado macatkunin 'quebrar' é uma estrutura transitiva sem incorporação, que possui o objeto direto remkalPin pojgan 'lança do convidado'. Quando o verbo incorpora o elemento possuído pojgən 'lança', o possuidor remkalPin 'convidado' não apenas permanece fora do complexo verbal, mas adquire uma relação gramatical de objeto direto com em (4b). Assim, este é um exemplo típico do subtipo de IN que denomino como "alçamento de possuidor"11 (possessor stranding), o qual será o foco do presente artigo. É importante dizer que ao final desse processo

${ }^{11}$ Conforme Baker (1988), possessor raising trata-se de uma construção em que tanto um nome possuidor quanto um nome possuído se tornam objetos de um predicado verbal, derivando-se, assim, uma sentença com dois objetos. Mais especificamente, um tipo de processo aplicativo seria o responsável por transformar uma construção genitiva em uma sentença com dois objetos. Ademais, de acordo com este autor, a denominação possessor stranding refere-se aos contextos sintáticos em que um nome possuído passa por incorporação e deixa o possuidor como um objeto sintático. Esta é a situação morfossintática que ocorre em Tenetehára e que denomino como "alçamento de possuidor" desde os trabalhos em Castro (2013, 2017). Deve-se destacar, no entanto, que outros autores o denominam de maneira distinta. Vieira (2010), por exemplo, traduz possessor raising como "alçamento de possuidor" e possessor stranding como "ascensão de possuidor", ao passo que Dourado (2001: 190) refere-se aos contextos de possessor stranding na língua Panará (Jê) como "alçamento de possuidor". 
sintático, a configuração sintática resultante preserva a valência da estrutura transitiva inicial. Isso porque o núcleo do sintagma genitivo (possessee) se desloca para posição de núcleo de $v^{0}$, deixando o DP possuidor (possessor) in situ, conforme a configuração arbórea abstrata delineada a seguir:

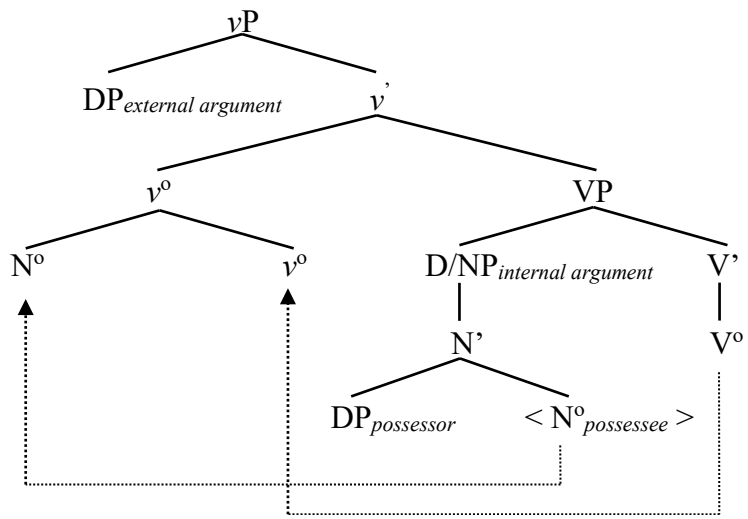

Ademais, pode-se constatar, translinguisticamente, pelo menos mais uma outra variação de "alçamento de possuidores". Nesses contextos, o sintagma genitivo - cujo núcleo $\mathrm{N}^{\circ}$ se move para a posição de $v^{0}$-, é o sujeito de uma predicação verbal intransitiva ao invés de um objeto direto. Como corolário disso, o possuidor que se torna órfão, sendo promovido, adquire uma relação gramatical de sujeito. Para fins de exemplificação, observe os seguintes exemplos da língua Mohawk: ${ }^{12}$

(6a) ka-rakv ne Sawatis hrao-nuhs-a?

$3 \mathrm{~N}$-ser.branco DET João 3M-casa-SUF

'A casa de João é branca'

(Postal 1962)

(6b) hrao-nuhs-rakv ne Sawatis

3M-casa-ser.branco DET João

'A casa de João é branca'

(Postal 1962)

Pode-se observar que, em (6a), o predicado verbal rakv 'ser branco' é uma estrutura intransitiva (inacusativa). Esse predicado verbal seleciona como seu sujeito o sintagma genitivo Sawatis hraonuhsa? 'a casa de João', o qual contém um DP possuído, a saber nuhs 'casa'. Quando esse DP possuído se incorpora em (6b), o possuidor Sawatis 'João'

Realmente, a literatura pertinente não é unânime em relação a estas traduções. Muito provavelmente possessor stranding pode ser traduzido tanto como "alçamento de possuidor" quanto como "ascensão do possuidor". Isto porque, de certa forma, o nome possuidor é alçado à posição de sujeito ou objeto; mas também ascende à função sintática de sujeito ou objeto, conforme o contexto. Diante destas considerações, vou manter no presente artigo a terminologia "alçamento de possuidor" para se referir ao que Baker (1988) chama de possessor stranding.

${ }^{12} \mathrm{~A}$ língua indígena canadense Mohawk pertence à Família linguística iroquoiana. 
exerce a função sintática de sujeito, conforme o diagrama abaixo adaptado a partir de Baker (1988):

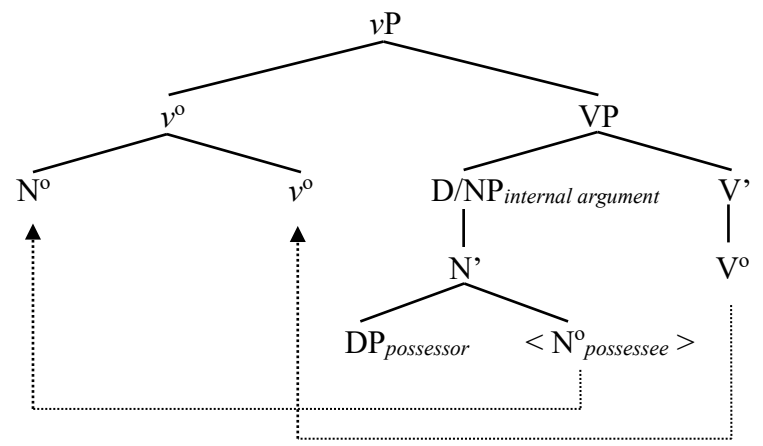

O presente artigo está organizado em 6 seções. Nesta seção, apresentei uma breve explicação teórica acerca da IN, bem como evidenciei as duas variações deste fenômeno, os quais ocorrem nas línguas Mapudungun, Chukchi e Mohawk; a saber: incorporação com e sem diminuição de valência. Na seção 2, exibo as classes aspectuais de Vendler (1967): estados, atividades, accomplishments e achievements. Na seção 3, analiso as ocorrências do fenômeno de IN em quatro línguas Tupí, a saber: Araweté, Tapirapé, Mundurukú e Tupí Antigo. Mais especificamente, verifica-se que nessas línguas também ocorrem as variações de incorporação analisadas a fim de evidenciar que tais línguas também apresentam os subtipos do fenômeno conforme constatado nas línguas Mapudungun, Chukchi e Mohawk. Na seção 4, passo, então, especificamente, à descrição do fenômeno da IN em Tenetehára. Além disso, busco investigar a IN com base em seu nível semântico. Isto deixará claro que existem diferenças entre o predicado sem IN e a estrutura com IN. Ademais, apuro evidências que direcionam sistematizações constantes que podem ser depreendidas a partir das distintas interpretações que serão evidenciadas. Para isso, aplicarei o quadro teórico de Vendler (1967) aos dados do Tenetehára. Na seção 5, teço as considerações finais. Finalmente, na seção 6, apresento alguns detalhes acerca da língua Tenetehára, sua classificação genética e as terras indígenas nas quais seus falantes habitam. Inicio, então, com as classes aspectuais de Vendler (1967).

\section{As classes aspectuais de Vendler (1967)}

Vendler (1967) foi o primeiro a propor que os verbos podem ser agrupados por meio de classes aspectuais. Assim, de acordo com o autor, os verbos nas línguas naturais podem ser divididos nas seguintes classes: estados, atividades, accomplishments e achievements. Para contrastar "atividades" com "estados", o autor faz uso da comparação que pode ser realizada por meio do seguinte par de exemplos:

(8) Estou correndo (ou escrevendo, trabalhando e assim por diante).

(9) Você sabe geografia? 
Note que "correr", em (8), remete a um processo em curso no tempo, ou seja, consiste em fases sucessivas que se seguem no tempo. Esse verbo representa um evento no qual quem está correndo, eleva sua perna direita em um momento, abaixa essa perna em um próximo instante e então ergue a outra perna, deixa-a cair, e assim por diante. Destarte, tal predicado verbal exibe o traço semântico denominado duratividade. Contudo, no exemplo em (9), o verbo "saber" não apresenta esta propriedade. Pode ser que alguém saiba geografia agora, todavia isso não significa que um processo de saber geografia esteja acontecendo no presente, consistindo-se em fases que se sucedem no tempo; por isso, é um predicado verbal que não progride ou se desenvolve em um intervalo de tempo.

Centrando-se nos verbos que exibem a propriedade de serem contínuos ou durativos, pode-se observar que eles apresentam uma interessante cisão; conforme se pode evidenciar por meio dos seguintes dados:

(10) O homem correu.

(11) O homem correu uma milha.

No exemplo em (10), se é verdade, por exemplo, que alguém correu por meia hora, então é verdade que ele correu por cada período dentro dessa meia hora. Por outro lado, em (11), mesmo que seja verdade que alguém tenha corrido uma milha em meia hora, não é verdade que ele tenha corrido uma milha em qualquer período de tempo durante essa meia hora. Parece, então, que "correr" e verbos dessa classe avançam no tempo de forma homogênea; assim, qualquer parte do processo apresenta a mesma natureza que o todo. A tal propriedade específica dá-se o nome de atelicidade. Não é assim com "correr uma milha"; esse composto verbo-objeto também apresenta a especificidade de avanço no tempo, mas ele segue em direção a um término que é logicamente necessário para ser o que ele é; o atributo semântico designado telicidade. Nas palavras de Vendler (1967), "de alguma forma, este clímax molda sua sombra para trás, dando uma nova cor a tudo o que foi antes"13 (Vendler 1967: 23).

Verbos como "correr" são denominados verbos de atividade; já predicados verbais como "correr uma milha" são chamados verbos de accomplishment. A próxima comparação analisada pelo autor pode ser observada por meio do seguinte par de exemplos:

(12) O alpinista alcançou o topo.

(13) O homem ama a mulher.

No exemplo em (12), "alcançar o topo" só pode ocorrer em um único momento, sendo pontual, instantâneo. ${ }^{14}$ Já o verbo "amar", em (13), tem um comportamento diferente uma vez que evidencia uma duração temporal. Assim, predicados verbais como "alcançar o

13 "Somehow this climax casts its shadow backward, giving a new color to all that went before" (Vendler 1967: 23).

${ }^{14}$ Contudo, Smith (1997: 19) afirma que "essa noção de instantâneo é conceitual, uma idealização (this notion of instantaneous is conceptual, an idealization)". Isso porque qualquer situação possui uma duração, mesmo que seu tempo de ocorrência seja muito reduzido e diminuto. 
topo" são denominados achievement, enquanto os verbos da classe a que pertence "amar" são referidos como predicados de estado.

A fim de evidenciar ainda mais a diferença entre os predicados de accomplishment $\mathrm{e}$ achievement definida por Vendler (1967), repito os exemplos (11) e (12) como (14) e (15) a seguir.

(14) O homem correu uma milha.

(15) O alpinista alcançou o topo.

Note que, em (14), o evento segue em direção a um término que é logicamente necessário para ser o que é; como já dito acerca do traço semântico telicidade. Ademais, ocorre um avanço no tempo, o traço semântico duratividade. Este é um predicado verbal de accomplishment.

Em (15), o traço semântico telicidade também pode ser percebido, já que apenas no momento em que o ponto final do evento é alcançado é que a sentença vai se tornar real. Contudo, o evento não é durativo, mas pontual. Tal predicado verbal é classificado como achievement.

De acordo com Verkuyl (1989), os atributos semânticos específicos de cada grupo de predicados verbais apontadas por Vendler (1967) podem ser traduzidas por meio dos seguintes traços semânticos binários: [+/- dinâmico], [+/- intervalo] e [+/- télico]. Nesse sentido, conforme Verkuyl (1989), os predicados verbais dinâmicos são aqueles constituídos de fases sucessivas que avançam no tempo. Assim, são processos em curso no tempo. Por isso, possuem o traço [+dinâmico]. Além disso, o conjunto de verbos que exibem duratividade, ou, em outras palavras, que apresentam um período de tempo significativo para sua realização, evidenciam o traço semântico [+intervalo]. Nesta linha de investigação, os predicados verbais nos quais os eventos atingem um ponto final, um resultado final claro, um fim que evidencia que eles ocorreram, revelam o traço semântico [+télico]. Cançado e Amaral (2016), baseadas, principalmente, em Vendler (1967) e Verkuyl (1989), propõem o seguinte quadro sinóptico:

Quadro 1: Classes aspectuais e traços semânticos

\begin{tabular}{l|l|l|l}
\hline \multirow{2}{*}{ Classe aspectual } & \multicolumn{4}{l}{ Traço semântico } & \multicolumn{2}{l}{} \\
\cline { 2 - 4 } & Dinâmico & Intervalo & Télico \\
\hline Estados & - & + & - \\
\hline Atividades & + & + & - \\
\hline Accomplishments & + & + & + \\
\hline Achievements & + & - & + \\
\hline
\end{tabular}

Fonte: Cançado e Amaral (2016: 166)

Ademais, ressalta-se o importantíssimo trabalho de Smith (1997) em que a autora propõe uma quinta classe de verbos, a saber, a dos predicados semelfactivos, que exibiriam o seguinte feixe de traços semânticos: [+ dinâmico, - intervalo, - télico]. Contudo, no presente artigo, opto por não explorar detalhes acerca dessa classe, uma vez que ela não é aceita de maneira unanime pela literatura pertinente. Para além da particularidade dos 
semelfactivos, o quadro acima se diferencia da análise de Smith (1997) pela seguinte inversão: a utilização do traço [+dinâmico] em lugar do traço [-estático]; o que, na prática, equivale à mesma propriedade semântica.

Na próxima seção, o intuito é investigar a IN em quatro línguas indígenas brasileiras, a fim de evidenciar que tais línguas também apresentam os subtipos do fenômeno conforme constatado nas línguas Mapudungun, Chukchi e Mohawk.

\section{IN nas línguas indígenas brasileiras Araweté, Tapirapé, Mundurukú e Tupí Antigo}

Conforme Solano (2009), também ocorre incorporação com diminuição de valência verbal na língua Araweté (Família Tupí-Guaraní, Ramo V). Observe os seguintes dados:

(16a) $i w i \quad k u \quad a-k a r \tilde{u}$

terra FOC 1-cavar

'Eu cavei terra'

(16b) a-iwi-karu $\quad k u \quad h e$

1-terra-cavar FOC 1

'Eu cavei terra'

(Solano 2009: 334)

Veja que, em (16a), o verbo transitivo karũ 'cavar' seleciona dois argumentos nucleares: o sujeito 'eu' representado pelo morfema de primeira pessoa $\{a-\}$ e o objeto $i w i$ 'terra'. Em (16b), por sua vez, há um processo sintático de incorporação do objeto, produzindo o predicado verbal intransitivo iwikarũ 'cavar terra'. De acordo com Solano (2009), os exemplos (16a) e (16b) acima

\footnotetext{
são indicação de que a composição nome.absoluto + verbo transitivo resulta em um verbo intransitivo, visto que não permite um objeto sintático. Esse tipo de combinação não poderia resultar em um verbo transitivo em Araweté, uma vez que um tema absoluto é naturalmente um elemento intransitivisador, como em "cavar-buraco", "revolver-terra", "comer-banana", fato que os impedem de requerer um objeto direto, uma vez que são intransitivos (Solano 2009: 335).
}

Note que esta variação de IN é semelhante ao exemplo do Chukchi em (2b). Dessa maneira, tanto em Mapudungun e Chukchi quanto em Araweté ocorre IN com diminuição de valência.

Já na língua Tapirapé (Família Tupí-Guaraní, Ramo IV), de acordo com Praça (2007), ocorrem dados em que, apesar de haver incorporação, não ocorre diminuição de valência, conforme se pode notar por meio do par de sentenças abaixo.

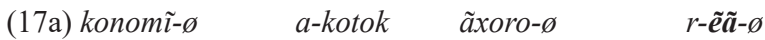

menino-REFER 3.I-cutucar papagaio-REFER R-Olho-REFER

'O menino cutucou o olho do papagaio'

(17b) konomĩ- $\quad$ a-ẽ ã-kotok ãxoro- $\varnothing$

menino-REFER 3.I-olho-cutucar papagaio-REFER

'O menino cutucou o olho do papagaio'

(Praça 2007: 134) 
Como se vê em (17a), o predicado kotok 'cutucar' é uma estrutura transitiva sem incorporação, a qual possui um objeto direto, o sintagma genitivo ãxoro rẽã 'olho do papagaio'. Quando o elemento possuído ẽ a 'olho' se incorpora, como em (17b), o possuidor ãxoro 'papagaio' permanece fora do complexo $\mathrm{N}^{0}+v^{0}$ e adquire a relação gramatical de objeto direto. Assim, ao final do processo morfossintático, a valência da estrutura transitiva inicial foi preservada, uma vez que apenas parte do objeto se incorporou ao verbo transitivo. Observe também que, para se incorporar, o nome possuído deve perder o prefixo relacional $\{r-\}$. Os exemplos em (17) são semelhantes aos dados em (4) da língua Chukchi, uma vez que se constituem em construções de "alçamento de possuidor".

Além disso, conforme Gomes (2008), a língua Mundurukú (Ramo Mundurukú) também apresenta o subtipo de "alçamento de possuidores" em que o sintagma genitivo é o sujeito da sentença, conforme os exemplos em (18) abaixo. Perceba que estas estruturas são semelhantes às configurações sintáticas que ocorrem na língua Mohawk apresentadas nos exemplos em (6).

(18a) ako dup $\quad o^{\prime}=(') a t$
bananeira R1.folha 3S=cair.PRF
'A folha da bananeira caiu'

(18b) ako $\quad o^{\prime}=$ tup $^{-}$'at

bananeira $3 \mathrm{~S}=\mathrm{R} 2$. folha-cair.PRF

'A folha da bananeira caiu'

(Gomes 2008: 36)

Em (18a), o verbo intransitivo 'at 'cair' tem como sujeito o sintagma genitivo [ako $d u p$ ] 'a folha da bananeira'. Já no exemplo em (18b), o núcleo nominal dup 'folha' se incorpora ao núcleo verbal 'at 'cair', gerando o complexo $\mathrm{N}^{0}+v^{0}$ tup' $a t$ 'folha-cair'. Note que após esse processo de IN, há o alçamento do complemento nominal do sintagma genitivo ako 'bananeira' para a função sintática de sujeito da sentença. Mais exatamente, em (18b), o possuidor do sintagma possessivo exerce a função sintática de sujeito da sentença quando o elemento possuído se move a partir da posição em que é gerado e se incorpora à esquerda do núcleo $v^{\circ}$, situação em que o complemento nominal permanece órfão - stranded, nos termos de Baker (1988).

Os dados do Tupí Antigo a seguir corroboram a asserção de que a IN é um fenômeno comum em outras línguas que compõem o tronco Tupí. Nesses exemplos, evidenciam-se mais uma vez, os seguintes tipos e subtipos desse fenômeno: incorporação total do objeto e incorporação parcial (núcleos) do objeto e sujeito, respectivamente.

\footnotetext{
IN COM DIMINUIÇÃo DE VALÊNCIA

(19a) $a-\hat{\imath}-k u a b \quad \boldsymbol{m b a} \boldsymbol{e}$

1SG-PO-saber coisas

'Sei as coisas'
}

(19b) a-mba'e-kuab

$1 \mathrm{SG}-$ coisas-saber

'Sei as coisas'

(Navarro 2005: 296) 
No exemplo em (19a), ocorre o verbo transitivo kuab 'saber', que seleciona os seguintes argumentos nucleares: o sujeito de primeira pessoa do singular, codificado por intermédio da unidade gramatical prefixal $\{a-\}$, e o objeto $m b a$ 'e 'coisas'. Já em (19b), o núcleo nominal mba'e 'coisas' se incorpora ao predicado verbal kuab 'saber', resultando em um novo predicado intransitivo, a saber: mba 'kuab 'coisas-saber'.

IN SEM DIMINUIÇÃO DE VALÊNCIA (ALÇAMENTO DO COMPLEMENTO NOMINAL A OBJETO)

(20a) a-îo-'ok moboîa akanga

1SG-PO-arrancar cobra cabeça

'Arranco a cabeça da cobra'

(20b) a-îlakang-'ok moboîa

1SG-PO-cabeça-arrancar cobra

'Decapito a obra'

(21a) $a-\hat{\imath}-k y t \tilde{\imath} \quad$ ybyrá $\quad r$-apó

1SG-PO-cortar árvore POSs-raiz

'Eu cortei a raiz da árvore'

(21b) a-s-apó-kytĩ $\quad$ ybyrá

1SG-PO-raiz-cortar árvore

'Eu cortei a raiz da árvore'

(Navarro 2005: 296)

Pode-se observar que, em (20a-21a), os predicados verbais 'ok 'arrancar' e kyti 'cortar' apresentam estruturas transitivas sem incorporação, as quais selecionam os sujeitos de primeira pessoa do singular realizados morfologicamente por meio do morfema $\{a-\}$ e do objetos, sintagmas genitivos, moboîa akanga 'a cabeça de cobra' e ybyrá rapó 'raiz da árvore', nessa ordem. Quando os verbos incorporam os núcleos akanga 'cabeça' e apó 'raiz', os complementos nominais moboîa 'cobra' e ybyrá 'árvore' não só permanecem fora dos complexos verbais, mas adquirem relações gramaticais de objetos diretos, como nos dados de (20a-21a).

IN SEM DIMINUIÇÃO DE VALÊNCIA (ALÇAMENTO DO COMPLEMENTO A SUJEITO)

(22a) xe py o-syryk

meu pé 3-escorregar

'Escorregou meu pé'

(22b) xe py-syryk

meu pé-escorregar

'Escorregou meu pé'

(23a) xe r-ugûy $\quad$ o-kanhem

meu poss-sangue 3-perder

'Perde-se-me o sangue' 


\section{CASTRO - INCORPORAÇÃO NOMINAL E ASPECTO LEXICAL...}

\section{(23b) xe r-ugîy-kanhem \\ meu poss-sangue-perder}

'Perde-se-me o sangue'(Lemos Barbosa 1956: 208)

Em (22a-23a), os predicados intransitivos syryk 'escorregar' e kanhem 'perder' selecionam como sujeitos os sintagmas genitivos xe py 'meu pé' e xe rugûy 'meu sangue', respectivamente. Já em (22b-23b), por sua vez, ocorrem processos morfossintáticos de incorporação dos núcleos possuídos $p y$ 'pé' e rugûy 'sangue' aos núcleos do $v \mathrm{P}$, gerando as estruturas complexas py-syryk 'pé-escorregar' e rugûy-kanhem 'sangue-perder'. Em síntese, nota-se que após a IN, os possuidores dos sintagmas possessivos passam a exercer a função de sujeito das sentenças. A seguir, passo, especificamente, à descrição do fenômeno de IN em Tenetehára. Como será notado, essa língua também apresenta os dois tipos de IN descritos anteriormente.

\section{IN em Tenetehára}

Na língua Tenetehára, de acordo com Castro $(2007,2013,2017)$ e Duarte e Castro (2010), é muito comum a incorporação do objeto a certos verbos transitivos, produzindo assim a diminuição no número dos argumentos que o verbo transitivo seleciona no componente sintático. Este mecanismo de incorporação é muito semelhante ao que se observou nas línguas Mapudungun, Chukchi, Araweté e Tupí Antigo nos exemplos em (1), (2), (16) e (19) evidenciados anteriormente. Nos dados a seguir, os predicados verbais exibem, visivelmente, um núcleo nominal incorporado à raiz verbal transitiva.

$\begin{aligned} & \text { (24a) o-poz awa pira a'e } \\ & \text { 3-alimentar homem peixe ele } \\ & \text { 'O homem alimenta peixe' }\end{aligned}$
$\begin{array}{lll}\text { (24b) } \begin{array}{l}\text { u-pira-poz awa } \\ \text { 3-peixe-alimentar homem }\end{array} \\ \text { 'O homem pesca' }\end{array}$

Em (24a), ocorre o verbo transitivo poz 'alimentar', o qual seleciona dois argumentos nucleares: o sujeito awa 'homem' e o argumento interno pira 'peixe'. Já em (24b), podese observar que o argumento interno se incorpora ao predicado verbal, derivando o verbo monoargumental pirapoz 'pescar', o qual seleciona apenas o sujeito awa 'homem'.

Note que, na derivação em (25) a seguir, o objeto pira 'peixe' se junta, por meio do movimento do núcleo $\mathrm{N}^{\circ}$ ao núcleo $v^{\circ}$ do predicado transitivo $p o z$ 'alimentar'. Assim, a operação de intransitivização do predicado verbal em (24b) pode ser melhor compreendida por meio da estrutura sintática abstrata delineada em (25). 
(25)

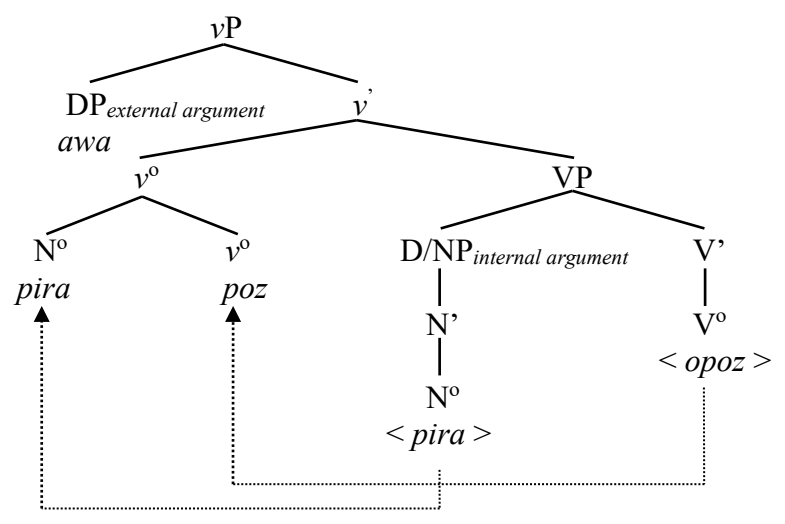

Com o intuito de corroborar as afirmações de que há, de fato, IN com diminuição de valência em Tenetehára, forneço os seguintes exemplos adicionais.

(26a) w-eityk awa pina a'e

3-jogar homem anzol ele

'O homem arremessou o anzol'

(26b) u-pina-eityk awa $t$ a'e

3-anzol-jogar homem ele

'O homem pescou'

(27a) $u$-'u tete-a'u awa ma'e a'e

3-comer INTS-AUM homem coisa ele

'O homem comeu muita coisa'

(27b) $u$-mai-'u tete-a'u awa $t$ a'e

3-coisa-comer INTS-AUM homem ele

'O homem comeu muito'

Em (26a) e (27a) ocorrem os verbos transitivos eityk 'jogar' e ' $u$ 'comer', os quais selecionam os seguintes argumentos nucleares: o sujeito awa 'homem' e os argumentos internos pina 'anzol' e ma'e 'coisa', respectivamente. Já em (26b) e (27b), pode-se observar que os' núcleos dos argumentos internos se incorporam à raiz verbal, derivando os predicados intransitivos pinaeityk 'pescar (lit.: arremessar anzol)' e mai'u 'comer (coisa)', respectivamente.

Ademais, a língua em análise também apresenta construções de "alçamento do possuidor" tanto de objeto, como em Chukchi, Tapirapé e Tupí Antigo, conforme exemplos (4), (17) e (20-21), quanto de sujeito, tais como em Mohawk, Mundurukú e Tupí Antigo, como se pode ver em (6), (18) e (22-23), respectivamente.

Isto pode ser constatado, porque em (28b) apenas parte do objeto, a saber: o nome possuído, núcleo do sintagma genitivo, incorpora-se ao núcleo do $v \mathrm{P}$ transitivo. Nesse exemplo, o resultado do processo não altera a estrutura transitiva inicial. Dessa forma, nas 
construções de "alçamento do possuidor", não existe diminuição de valência, apesar de haver incorporação.

\section{ALÇAMENTO DO OBJETO}

(28a) $u$-kixi awa ${ }_{\mathrm{DP}} \quad w-a^{\prime} y r$ i-po $\left.\quad\right] \quad a^{\prime} e$

3-cortar homem CORR-filho POSS-mão ele

'O homem cortou a mão do próprio filho'

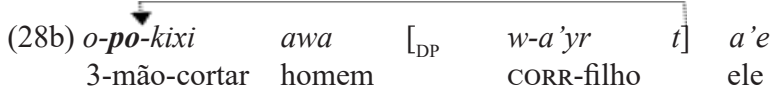

'O homem cortou a mão do próprio filho'

Em (28a), observa-se o verbo transitivo kixi 'cortar', o qual seleciona o sujeito awa 'homem' e, como objeto sintático, o sintagma genitivo, wa'yr ipo 'mão do filho'. Em (28b), por sua vez, verifica-se o processo morfossintático de incorporação do núcleo possuído po "mão" ao núcleo do $v^{\circ}$, gerando o núcleo verbal complexo $v^{\circ}+\mathrm{N}^{\circ}$ ainda transitivo pokixi 'mão-cortar'. Assim, o argumento possuído do sintagma possessivo desloca-se de sua posição de base, incorporando-se à raiz verbal. Ademais o possuidor do sintagma possessivo é alçado à função sintática de objeto da sentença. Isto pode ser melhor compreendido por meio da estrutura sintática abstrata delineada em (29).

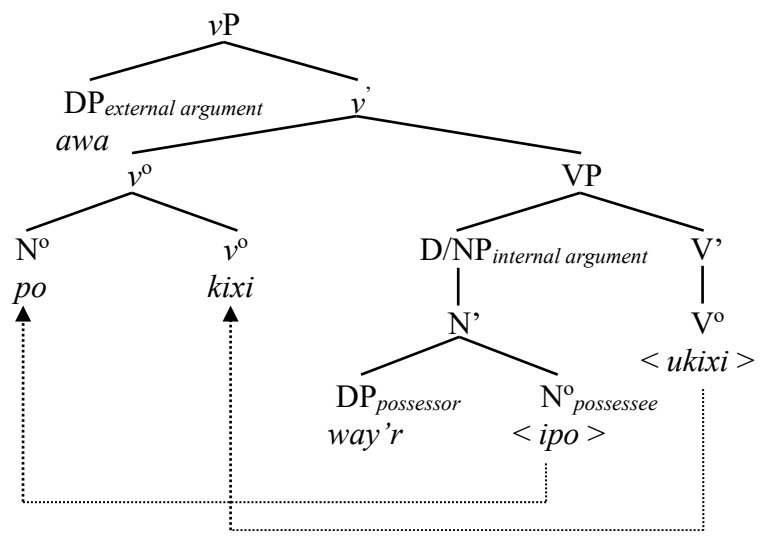

Finalmente, apresento abaixo um par de sentenças em Tenetehára que variam quanto ao processo de IN. Nota-se que em (30b), há o "alçamento de possuidor" para a função sintática de sujeito da sentença, como pode ser notado a seguir.

ALÇAMENTO DO SUJEITO

(30a) u-hem kwarer h-uwi a'e

3-sair menino 3-sangue ele

'O menino sangrou' (Lit.: o sangue do menino saiu) 
(30b) $\left.\begin{array}{c}\text { i-huwi-hem } \\ \text { 3-sangue-sair }\end{array} \quad \begin{array}{ll}{ }_{\mathrm{DP}} \text { kwarer } & t\end{array}\right] \begin{aligned} & a^{\prime} e \\ & \text { menino }\end{aligned}$
'O menino sangrou' (Lit.: o sangue do menino saiu)

Note que, em (30a), o predicado verbal intransitivo hem 'sair' seleciona um único argumento nuclear cuja função sintática é a de sujeito, a saber: kwarer huwi 'sangue do menino'. Em (30b), por sua vez, ocorre a incorporação do núcleo possuído $u w i$ 'sangue'. Portanto, o possuidor $k$ warer 'menino' é alçado, adquirindo a relação gramatical de sujeito, como evidencio a partir da configuração arbórea abstrata delineada em (31) abaixo:

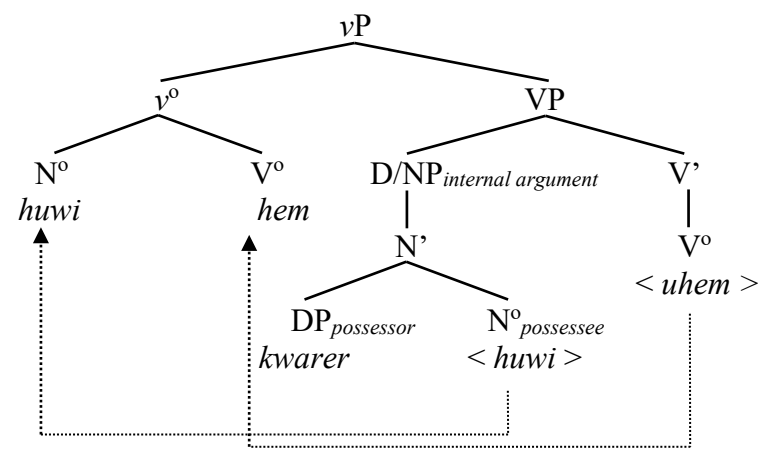

$\mathrm{Na}$ próxima seção, busco investigar as propriedades semânticas envolvidas nas construções de "alçamento de possuidor" a objeto em Tenetehára. O que pode ser notado é que existem diferenças semânticas entre o predicado sem IN e a estrutura com IN.

\subsection{Incorporação e semântica nas construções de alçamento de objeto}

Na língua Tenetehára, em algumas construções, podem existir diferenças semânticas entre a versão com um núcleo incorporado e a versão sem incorporação. Isso pode ser notado por meio dos seguintes dados:

(32a) o-'ok awa miar i-àkàg a'e

3-tirar homem animal poss-cabeça ele

'O homem tirou a cabeça do animal' (Propositalmente)

(32b) $u$-zàkàg-ok awa miar a'e

3-cabeça-tirar homem animal ele

'O homem decapitou o animal' (Acidentalmente)

(33a) u-kutuk awa w-a'yr h-eme a'e

3-furar homem CORR-filho POss-lábio ele

'O homem fura o lábio do (próprio) filho' (Propositalmente) 


\section{CASTRO - INCORPORAÇÃO NOMINAL E ASPECTO LEXICAL...}

(33b) w-eme-kutuk awa w-a'yr a'e

3-lábio-furar homem CORR-filho ele

'O homem fura o lábio do (próprio) filho'

(34a) u-kixi awa w-a'yr i-po a'e

3-cortar homem CORR-filho POSS-mão ele

'O homem corta a mão do (próprio) filho'

(34b) o-po-kixi awa w-a'yr a'e

3-mão-cortar homem CORR-filho ele

'O homem cortou a mão do (próprio) filho'
(Acidentalmente)

(Propositalmente)

Como se pode notar, nos dados em (32a-34a), os falantes da língua Tenetehára relatam que o evento foi proposital; contudo, em (32-34b), eles afirmam que o evento foi acidental.

Uma questão teórica que deverá ser discutida em trabalhos posteriores é a de que a relação biunívoca entre as estruturas semântica e sintática parecem não serem preservadas nesta língua. Isso é evidenciado pelas observação dos pares mínimos de INs em Tenetehára e suas diferenças de interpretação (32-34). Assim, a Hipótese da Uniformidade de Atribuição Theta (Uniformity of Theta Assignment Hyphotesis - UTAH), conforme fora estipulada em Baker (1988) não é satisfeita e precisa ser mais bem flexibilizada a fim de dar conta dos dados de IN da língua Tenetehára.

Na próxima subseção, o intuito é buscar pistas que direcionem a uma organização constante a partir do paradigma de interpretação apresentado, por exemplo, nos exemplos de (32-34) acima, aplicando o quadro teórico de Vendler (1967) aos dados do Tenetehára.

\subsection{As classes aspectuais a Incorporação Nominal em Tenetehára}

Para responder qual organização constante se pode depreender por paradigma de interpretação apresentado anteriormente, observe o par de sentenças em (32), repetidas abaixo como (35), para efeitos de simplificação.

(35a) $o$-'ok awa miar i-àkàg a'e

3-tirar homem animal Poss-cabeça ele

"O homem tirou a cabeça do animal" (Propositalmente)

(35b) $u$-zàkàg-ok awa miar a'e

3-cabeça-tirar homem animal ele

"O homem decapitou o animal" (Acidentalmente)

Conforme visto na seção 2, o feixe de traços semânticos binários [+/-dinâmico], [+/-intervalo] e [+/-télico] é capaz de definir a classe aspectual a que um predicado verbal faz parte. A hipótese que defenderei neste artigo é a de que as estruturas sem IN podem ter uma leitura de predicados de accomplishments, enquanto as configurações verbais com IN geram complexos verbais que obrigatoriamente se comportam como predicados 
de achievement. Passemos, então, à análise dos traços semânticos envolvidos em cada predicado.

Concernentemente ao traço [+/-intervalo], o evento descrito pelo verbo 'ok 'cortar', de (35a), pertence ao conjunto de predicados verbais que exibem duratividade, ou seja, um período de tempo significativo para sua realização; apresentando, assim, o traço semântico [+intervalo]. Por isso, pode-se dizer: 'O homem tirou cabeça do animal em uma hora'. Diferentemente, em (35b), àkàgok 'decapitar' possui o traço semântico [-intervalo]. Assim, ele é um predicado verbal sem duratividade, e, por isso, com pontualidade temporal. Nessa linha de raciocínio, sintagmas adverbiais (ou advérbios) que denotem situações instantâneas como, por exemplo, às 10 horas, são compatíveis com esse verbo. Nesse sentido, as sentenças: "O homem decapitou a cabeça do animal às 10 horas" ou "O homem decapitou a cabeça do animal rapidamente" são bem formadas.

Nesta linha de investigação, a presença ou ausência do traço [intervalo] em construções com e sem incorporação pode ser bem ilustrada com exemplos que incluem os advérbios "rapidamente" e "lentamente". O advérbio "lentamente" descreveria processos com duração maior, enquanto que "rapidamente" pode ser associado a eventos com menor duração. Curiosamente, na língua Tenetehára, o advérbio na'arewahy 'rapidamente' pode coocorrer em estruturas com e sem IN; contudo, o advérbio zàrew 'lentamente' gera sentenças agramaticais quando utilizado em contextos de IN. Esse fato indica que as estruturas com IN geram complexos verbais que evidenciam o traço semântico [-intervalo]. Observe os exemplos abaixo:

(36a) o-'ok zàrew awa miar i-àkàg a'e

3-tirar lentamente homem animal poss-cabeça ele

'O homem tirou lentamente a cabeça do animal'

(36b) o-'ok na'arewahy awa miar i-àkàg a'e

3-tirar rapidamente homem animal Poss-cabeça ele

'O homem tirou rapidamente a cabeça do animal'

(36c) *u-zàkàg-ok zàrew awa miar a'e

3-cabeça-tirar lentamente homem animal ele

'(?)O homem decapitou lentamente o animal'

(36d) u-zàkàg-ok na'arewahy awa miar a'e 3-cabeça-tirar rapidamente homem animal ele 'O homem decapitou rapidamente o animal'

(37a) u-kutuk zàrew awa w-a'yr h-eme a'e

3-furar lentamente homem CORR-filho POSS-lábio ele

'O homem fura lentamente o lábio do (próprio) filho'

(37b) u-kutuk na'arewahy awa w-a'yr h-eme a'e 3-furar rapidamente homem CORR-filho POss-lábio ele

'O homem fura rapidamente o lábio do (próprio) filho' 

(37c) *w-eme-kutuk

\section{zàrew}
awa
$w-a$ 'yr
a'e
3-lábio-furar
lentamente homem CORR-filho ele
'O homem fura lentamente o lábio do (próprio) filho'
(37d) w-eme-kutuk na'arewahy awa w-a'yr a'e 3-lábio-furar rapidamente homem CORR-filho ele
'O homem fura rapidamente o lábio do (próprio) filho'

Os dados agramaticais apresentados em (36c) e (37c) atestam que o contexto de IN "alçamento de objeto" restringe a ocorrência do advérbio "lentamente", indicando que esse evento apresenta o traço semântico [-intervalo], sendo por isso não durativo. Note que o evento descrito nos dados sem incorporação - (36ab) e (37ab) - pode ocorrer avançando no tempo de forma homogênea ou pontualmente. Todavia, o evento descrito em estruturas de IN só se realiza totalmente em um único momento, sendo pontual e instantâneo; ou pelo menos, apresenta um tempo de ocorrência bastante diminuto. Este último comportamento se adequa à definição da propriedade semântica [-intervalo] conforme definido por Vendler (1967).

O fato de as versões sem incorporação nominal poderem coocorrer com os advérbios zàrew 'lentamente' e na'arewahy 'rapidamente' não são um problema para a presente análise. Isto porque se pode produzir contextos marcados em que o advérbio na arewahy 'rapidamente' figure em construções sem incorporação. Contudo, as construções com IN são sempre agramaticais quando coocorrem com o advérbio zàrew 'lentamente', já que o traço [-intervalo] parece ser incompatível com este tipo de configuração sintática.

Em relação ao traço [+/-dinâmico], os verbos 'ok 'cortar' e àkàgok 'decapitar' exibem o traço [+dinâmico]. Isso porque são constituídos de fases sucessivas que avançam no tempo; ou seja, são processos em curso. Estes verbos contrastam com o verbo kwaw 'saber/conhecer', por exemplo, o qual se constitui em um predicado verbal de estado que, devido a isso, não se constitui em um processo que prossegue temporalmente, apresentando o traço [-dinâmico], conforme o exemplo em (38) a seguir.

\section{(38) zawar u-kwaw u-zar a'e cachorro 3-conhecer CORR-dono ele 'O cachorro conhece o seu dono'}

Finalmente, no que se refere ao traço semântico [+/-télico], tanto o evento conectado ao predicado verbal 'ok 'cortar' quanto aquele vinculado ao verbo àkàgok 'tirar cabeça' possuem o traço semântico [+télico]. Isto porque eles devem atingir um ponto final ou clímax, um resultado final claro. Assim, o traço telicidade pode ser constatado nesses dois predicados verbais, tendo em vista que este traço conduz a um término que é logicamente necessário para ser o que ele é, conforme Vendler (1967). Essa característica é distinta do que ocorre, por exemplo, com o verbo eta 'ter', o qual possui o traço [-télico], porque descreve uma situação uniforme, tendo em vista não exigir que se chegue a um resultado final para que a sentença seja verdadeira, como no dado abaixo. 
(39) h-eta Ywyrahu h-àpuz a'e

3-ter Ywyrahu 3-casa ele

'Ywyrahu tem uma casa'

Desta forma, associando os traços apresentados em relação aos predicados 'ok 'cortar' e àkàgok 'decapitar', chega-se ao seguinte padrão em (40), o qual permite a classificação dos verbos em questão como accomplishment ou achievement, conforme a seguir:

(40) 'ok = [+dinâmico], [+intervalo], [+télico $]=$ accomplishment

àkàg-ok $=[+$ dinâmico $], \quad[-$ intervalo $],[+$ télico $]=$ achievement

Veja que é exatamente o traço semântico [+/-intervalo] a propriedade que define a distinção entre accomplishments e achievements e é precisamente a mudança gerada via IN. A análise realizada por meio dos advérbios zàrew 'lentamente' e na'arewahy 'rapidamente' para os exemplos em (36-37) pode ser estendida para os exemplos (32-34). Observe, novamente os dados em (32) retomados como (41) abaixo.

(41a) o-'ok awa miar i-àkàg a'e

3-tirar homem animal poss-cabeça ele

'O homem tirou a cabeça do animal' (Propositalmente)

(41b) u-zàkàg-ok awa miar a'e

3-cabeça-tirar homem animal ele

'O homem decapitou o animal' (Acidentalmente)

Imagine um contexto em que alguém crie galinha pra comer. Logo, no momento do abate do animal, a pessoa deliberadamente retira a cabeça da galinha com uma faca. Isso geralmente ocorre de forma durativa, o que evidencia o traço [+intervalo] e sua conexão com a interpretação "propositalmente", como em (41a). Contudo, conceba uma outra circunstância em que uma pessoa tenha uma galinha de estimação e ocorra um acidente. Mais exatamente, neste contexto, o indivíduo estará com uma faca em sua mão, ele cai e, sem querer, decapita a galinha. Evidentemente, está presente o traço [-intervalo], bem como a interpretação "acidentalmente", de acordo com (41b).

Adicionalmente, note que as interpretações fornecidas (propositalmente $\mathrm{x}$ acidentalmente) evidenciam uma importante distinção entre verbos de accomplishments e achievements, a saber: o primeiro se constitui de subeventos enquanto o segundo não tem essa característica, sendo monoeventivo. Ademais, Dowty (1979) assinala a complexidade dos eventos como quesito para se distinguir predicados verbais de accomplishment e de achievements. Destarte, os verbos de accomplishments indicam eventos complexos que abarcam um ponto inicial e um ponto final; ao passo que os predicados de achievements se referem a eventos ininterruptos e simples, já que não englobam subeventos em sua constituição interna.

Diante das afirmações acima, a leitura "propositalmente" evidenciada nos exemplos de (32-34a), por um lado, e "acidentalmente", em (32-34b), por outro, podem ser devidamente explicadas. Nessa perspectiva, verbos de accomplishments têm uma maior propensão do que predicados de achievements a serem realizados de forma deliberada. 
Isso é comprovado porque é mais comum que uma sequência de subeventos ocorra de forma premeditada do que um evento pontual. A análise fica mais evidente com a situação oposta: os predicados verbais de achievements têm maior tendência a serem acidentais, já que denotam eventos instantâneos e simples. Para outros exemplos, observe os dados do português abaixo. ${ }^{15}$

\section{ACCOMPLISHMENT}

(42) O menino arrumou a gaiola do passarinho, propositalmente.

(43) O menino arrumou a gaiola do passarinho, *acidentalmente.

\section{ACHIEVEMENT}

(44) O menino quebrou o espelho que amava, propositalmente.

(45) O menino quebrou o espelho que amava, acidentalmente.

Finalizada a aplicação das análises acima, na próxima seção, apresento as considerações finais e, logo após, dedico uma outra seção para questões acerca da autodenominação, localização geográfica e filiação linguística deste povo e língua.

\section{Considerações Finais}

O objetivo deste artigo foi investigar o mecanismo de IN na língua Tenetehára e sua relação com as classes aspectuais propostas por Vendler (1967). O mecanismo de IN se dá por meio de pelo menos dois tipos: (i) incorporação total do objeto no núcleo $v^{\circ}$ e (ii) incorporação do núcleo do sintagma genitivo no núcleo do $v \mathrm{P}$. Na incorporação total, o objeto direto, ao se incorporar ao predicado verbal, pode gerar um predicado que se comporta como um verbo intransitivo. Todavia, nas construções de "alçamento do possuidor", apenas parte do sujeito ou do objeto, a saber: o núcleo $\mathrm{N}^{\circ}$, núcleo do sintagma genitivo, pode se incorporar ao núcleo do $\mathrm{vP}$. O resultado desse processo não altera a estrutura transitiva inicial. Logo, nas construções de "alçamento do possuidor" não existe diminuição de valência, apesar de haver IN. Ademais, em relação ao plano semântico nas construções de "alçamento do possuidor" à função sintática de objeto, o que tenho observado é que os falantes dessa língua costumam apontar duas interpretações distintas, uma para a versão sem incorporação e outra interpretação para a versão com IN. Assim, pretendi responder qual organização constante se pode depreender do paradigma de interpretação apresentado. A hipótese lançada em relação às diferenças de interpretação entre o predicado sem IN e a estrutura com IN tem a ver com a noção de aspecto verbal e com as definições de accomplishment e achievement nos termos de Vendler (1967). Neste sentido, defendi que construções sem IN podem se comportar como a classe semântica de predicados verbais de accomplishment; já e as versões com IN abrangem sempre os predicados de achievement.

O objetivo da próxima seção é analisar questões referentes à autodenominação, localização geográfica e filiação linguística deste povo e língua. É importante ressaltar que

${ }^{15}$ Interpretações diferentes são muito marcadas. 
toda esta seção está intimamente baseada em Camargos $(2013,2017)$ e Castro; Camargos e Guajajara (2019), para além da bibliografia referenciada.

\section{Povo e língua}

O intuito dessa seção é proporcionar informações acerca da autodenominação e localização geográfica deste povo indígena; bem como tecer dados referentes à classificação da língua Tenetehára. Inicio com questões acerca da autodenominação do povo em questão.

\subsection{Autodenominação}

Além de ser conhecido como Guajajára, este povo indígena se autodenomina como Tenetehára, que, conforme Boudin (1978: 260), significa "a gente, os índios em geral e mais especificamente os índios Tembé e Guajajára". Relativamente à derivação morfológica para o processo de formação de palavra, podemos observar o seguinte:

(46) t-en-ete-har $\rightarrow$ Tenetehára

$3 \mathrm{G}$-Ser-ENF-NOML

'A gente verdadeira'

O termo Tenetehára inclui os Guajajara e os Tembé. Sendo mais preciso, a denominação Tenetehára faz referência tanto aos Guajajára, que residem no estado do Maranhão, quanto aos Tembé, os quais habitam o Pará. Os nomes Guajajára e Tembé apresentam a seguinte segmentação morfológica:

(47) wazay-zar $\quad \rightarrow \quad$ Guajajára

cocar-NOML

'O dono do cocar'

(48) $x i \quad$ i-pew $\quad \rightarrow \quad$ Tembé

nariz 3-achatado

'O nariz é achatado'

Consoante Camargos (2013: 18-19), os Tenetehára, Guajajára e Tembé podem também receber denominações que identificam a localização geográfica em que habitam, conforme abaixo.

(49) wàmà-iwar-wà

Guamá-NOML-PL

'Aqueles do rio Guamá'

(50) turi-war-wà

alegre-NOML-PL

'Aqueles do rio Turiaçu' 
(51) kuripi-war-wà Gurupi-NOML-PL

'Aqueles do rio Gurupi'

(52) miàri-war-wà

Mearim-NOML-PL

'Aqueles do rio Mearim'

(53) namà-iwar-wà

mar-NOML-PL

'Aqueles da margem do mar (Barra do Corda)'

(54) pinare-iwar-wà

Pindaré-NOML-PL

'Aqueles do rio Pindaré'

(55) zutyw-iwar-wà

Zutiwa-NOML-PL

'Aqueles do rio Zutiwa'

(56) murixityw-iwar-wà

Buriticupu-NOML-PL

'Aqueles do rio Buriticupu'

Na subseção seguinte, o intuito é evidenciar a localização em que os Guajajaras e os Tembés habitam.

\subsection{Localização geográfica}

Segundo Duarte (1997, 2003, 2007), todas as terras indígenas habitadas pelo povo Guajajára estão localizadas na região central do estado do Maranhão, mais exatamente nas regiões dos seguintes rios: Pindaré, Grajaú, Mearim e Zutiwa. As terras são cobertas pelas florestas altas da Amazônia, bem como pelas matas de cerradão, que são matas de transição entre as florestas amazônicas e os cerrados. Já os Tembé habitam sobretudo as florestas de mata alta do leste do Pará, fronteira com o Maranhão. Nada obstante, uma parte do povo Tembé vive na margem direita do rio Gurupi, no estado do Maranhão. Na Figura 1, apresentamos a localização das Terras Indígenas Tenetehára. 
Figura 1: Localização das Terras Indígenas Tenetehára

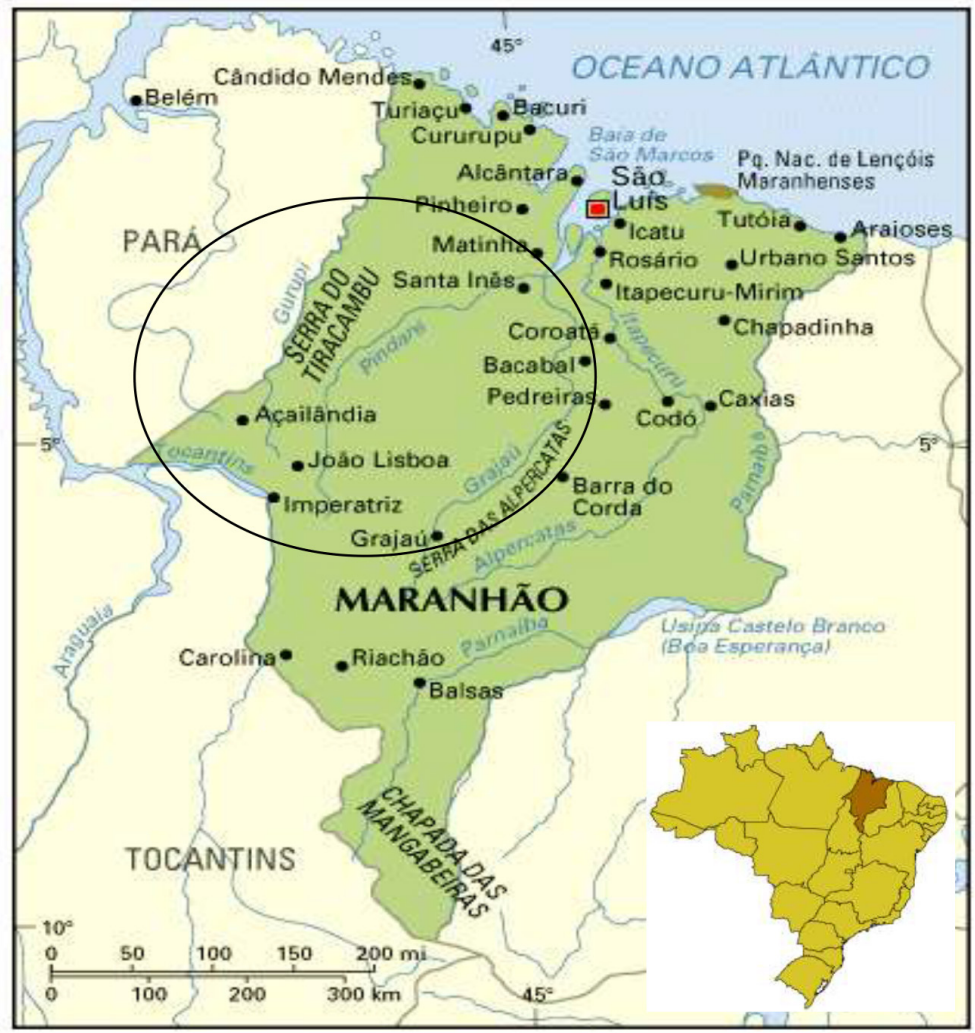

(Fonte: Castro 2007)

O objetivo da próxima subseção é apresentar o tronco, a família e o sub-ramo linguísticos em que o Tenetehára está classificado.

\subsection{Filiação linguística}

As línguas indígenas do Brasil, por apresentarem semelhanças morfofonológicas nas suas origens, tornam-se parte de grupos linguísticos que são denominados como famílias linguísticas. Essas famílias, por sua vez, fazem parte de grupos maiores que são designados como troncos linguísticos.

No Brasil, os troncos mais conhecidos e com uma quantidade maior de línguas são o Tupí e o Macro-Jê. Além desses dois troncos, há também mais 19 famílias que, por não possuírem taxas suficientes de semelhanças, não são agrupadas em troncos. E, por fim, há também as línguas isoladas, que por não terem uma quantidade satisfatória de similaridade entre si ou outras línguas indígenas brasileiras, não são agrupadas em famílias linguísticas. 
O tronco Tupí se subdivide em dois ramos; a saber: o ocidental e o oriental; estes, por sua vez, subdividem-se em famílias linguísticas; conforme o quadro abaixo o qual foi formulado a partir de Rodrigues (1984-1985); Rodrigues; Cabral (2002) e Dietrich (2010):

Quadro 2: Tronco Tupí

\begin{tabular}{|l|l|}
\hline \multicolumn{1}{|c|}{ Ramo } & \multicolumn{1}{|c|}{ Família Linguística } \\
\hline \multirow{4}{*}{ Ocidental } & Poruborá-Ramarama \\
\cline { 2 - 3 } & Mondé \\
\cline { 2 - 3 } & Tupari \\
\cline { 2 - 2 } & Arikém \\
\hline \multirow{4}{*}{ Oriental } & Juruna \\
\cline { 2 - 2 } & Munduruku \\
\cline { 2 - 2 } & Mawé-Aweti \\
\cline { 2 - 2 } & Tupí-Guaraní \\
\hline
\end{tabular}

Fonte: Camargos (2017: 89)

De acordo com Rodrigues (1984-1985), a língua Tenetehára pertence à família TupíGuaraní. Ademais, as seguintes línguas também possuem semelhanças suficientes para serem agrupadas em um grupo. Neste sentido, o Ramo IV é constituído pelas seguintes línguas: Assuriní do Tocantins, Avá-Canoeiro, Parakanã, Suruí e Mudjetíre, Suruí do Tocantins e Tapirapé; além do Tembé e do Guajajara. Diante disso, Camargos (2017) formulou o quadro abaixo a partir de Rodrigues (1984-1985), Rodrigues; Cabral (2002) e Dietrich (2010).

Quadro 3: Família Tupí-Guaraní16

\begin{tabular}{|c|l|}
\hline Ramo & \multicolumn{1}{|c|}{ Línguas } \\
\hline I & $\begin{array}{l}\text { *Guaraní antigo, Avá/ Nhadeva, Caiová, Guarani pa- } \\
\text { raguaio, Mbyá, Xetá, Guarani do Chaco/ Chiriguano, } \\
\text { Tapiete. }\end{array}$ \\
\hline II & Guarayo, Guarasug'wã, Pauserna, Siriono, Yuki, Aché. \\
\hline III & $\begin{array}{l}\text { *Tupinambá, *Tupiniquim, *Potiguara, Nheengatu, } \\
\text { (Cocama), (Omágua). }\end{array}$ \\
\hline IV & $\begin{array}{l}\text { Assurini do Tocantins, Tapirapé, Parakanã, Suruí e } \\
\text { Mudjetíre, Tembé, Guajajára, Avá-Canoeiro. }\end{array}$ \\
\hline V & Anambé, Amanayé, Araweté, Asurini do Xingu, Kayabi. \\
\hline VI & $\begin{array}{l}\text { Parintintin, Apiaká, Amondawa, Kawahib/ Uru-eu-wau- } \\
\text {-wau. }\end{array}$ \\
\hline VII & Kamayurá. \\
\hline VIII & $\begin{array}{l}\text { Wayãpi, Wayampipuku, Émérrillon, Zo'é, Guajá, } \\
\text { Ka'apor. }\end{array}$ \\
\hline
\end{tabular}

\footnotetext{
${ }^{16} \mathrm{O}$ asterisco $\left(^{*}\right)$ marca uma língua extinta.
} 
Fonte: Camargos (2017: 89)

A família Tupí-Guaraní é a família linguística que evidencia a maior distribuição geográfica, uma vez que existem línguas dessa família não só em todas as regiões do Brasil como também em vários outros países da América Latina, tais como: Argentina, Bolívia, Colômbia, Guiana Francesa, Paraguai, Peru e Venezuela.

\section{Referências}

Baker, Mark (1988). Incorporation. Chicago: University of Chicago Press.

Baker, Mark (1995). Lexical and nonlexical noun incorporation. In Urs Egli; Peter E. Pause; Christoph Schwarze; Arnim von Stechow; Götz Wienold (eds.), Lexical knowledge in the organization of language, pp. 3-34. Amsterdam: John Benjamins.

Baker, Mark (1996). The polysynthesis parameter. Oxford: Oxford University Press.

Baker, Mark (2009). Is head movement still needed for noun incorporation? The case of Mapudungun. Lingua 119: $148-165$.

Baker, Mark; Aranovich, Roberto; Golluscio, Lucia (2005). Two types of syntactic noun incorporation: noun incorporation in Mapudungun and its typological implications. Language 81: 138-176.

Boudin, Max Henri (1978). Dicionário de Tupi moderno: Dialeto tembé-ténêtéhar do alto rio Gurupi. São Paulo: Conselho Estadual de Artes e Ciências Humanas.

Camargos, Quesler Fagundes (2013). Estruturas causativas em Tenetehára: Uma abordagem minimalista (Dissertação de mestrado em linguística). Belo Horizonte: Universidade Federal de Minas Gerais.

Camargos, Quesler Fagundes (2017). Aplicativização, causativização e nominalização: Uma análise unificada de estruturas argumentais em Tenetehára-Guajajára (Família Tupi-Guarani) (Tese doutorado em linguística). Belo Horizonte: Universidade Federal de Minas Gerais.

Camargos, Quesler Fagundes; Castro, Ricardo Campos; Guajajára; Taywan Morais Clemente. (2019). Os Tenetehára e a festa da menina-moça: os trajes tradicionais e seus significados. Revista Verbo de Minas 20(36): 46-60. https://seer.cesjf.br/index.php/verboDeMinas/article/view/2176/1462

Cançado, Márcia; Amaral, Luana (2016). Introdução à semântica lexical: Papéis temáticos, aspecto lexical e decomposição de predicados. Petrópolis, RJ: Editora Vozes.

Castro, Ricardo Campos (2007). Interface morfologia e sintaxe em Tenetehára (Dissertação de mestrado em linguística): Belo Horizonte: Faculdade de Letras, Universidade Federal de Minas Gerais.

Castro, Ricardo Campos (2013). O epifenômeno da alternância de valência em Tenetehára (Tupí-Guaraní). Revista da ANPOLL 1: 347-391. https://revistadaanpoll.emnuvens.com.br/revista/article/view/674 https://doi.org/10.18309/anp.vli34.674

Castro, Ricardo Campos Castro (2017). Morfossintaxe Tenetehára (Tupi-Guaraní) (Tese de doutorado em linguística). Belo Horizonte: Universidade Federal de Minas Gerais. 


\section{CASTRO - INCORPORAÇÃO NOMINAL E ASPECTO LEXICAL...}

Chomsky, Noam (1981). Lectures on government and binding. Dordrecht: Foris.

Dietrich, Wolf (2010). Tipología morfosintáctica y clasificación de las lenguas tupí-guaraníes. In Marisa Censabella; Raúl González (eds.), Libro de Actas II Encuentro de Lenguas Indígenas Americanas y II Simposio Internacional de Lingüística Amerindia Asociación de Lingüistica y Filología de América Latina (ALFAL) 17-19 de septiembre de 2009. Resistencia, Chaco. Buenos Aires: CONICET.

Dourado, Luciana Gonçalves (2001). Aspectos morfossintáticos da língua panará (Jê) (Tese de doutorado em linguística): Campinas, SP: Universidade Estadual de Campinas. Disponível em: http://www.repositorio. unicamp.br/handle/REPOSIP/269111

Dowty, David (1979). Word meaning and Montague grammar. Reidel, Dordrecht.

Duarte, Fábio Bonfim (1997). Análise gramatical das orações da língua Tembé (Dissertação mestre em linguística). Brasília, DF: Instituto de Letras, Universidade de Brasília.

Duarte, Fábio Bonfim (2003) Ordem dos constituintes e movimento em Tembé: Minimalismo e anti-simetria (Tese doutor em linguística): Belo Horizonte: Faculdade de Letras, Universidade Federal de Minas Gerais.

Duarte, Fábio Bonfim (2007). Estudos de morfossintaxe Tenetehára. Belo Horizonte: Faculdade de Letras da Universidade Federal de Minas Gerais.

Duarte, Fábio Bonfim; Castro, Ricardo Campos (2010). Inergatividade, estrutura causativa e incorporação nominal em Tenetehára. In Ana Suelly Arruda Câmara Cabral; Aryon Dall’Igna Rodrigues; Fábio Bonfim Duarte (orgs.), Línguas e Culturas Tupí, pp. 43-62. Campinas: Curt Nimuendajú.

Gomes, Dioney Moreira (2008). Incorporação nominal em Mundurukú (Tupí). Ameríndia 1 (31): 19-59. Disponível em:

https://www.vjf.cnrs.fr/sedyl/revues.php?aire=CELIA\&revue=Amerindia\&langue=fr\&voirintro=N\&voi rliste $=\mathrm{N} \&$ annee $=\&$ num $r e v=\&$ bool $2=$ ou $\&$ auteurs $=$ Gomes + D.M.

Lemos Barbosa, Antônio (1956). Curso de Tupi Antigo: Gramática, exercícios, textos. Rio de Janeiro: Livraria São José.

Mithun, Marianne (1984). The evolution of noun incorporation. Language 60(4): 847-894.

Navarro, Eduardo de Almeida (2005). Método moderno de Tupi Antigo: A língua do Brasil dos primeiros séculos. São Paulo: Editora Global.

Postal, Paul (1962). Some syntactic rules of Mohawk (Tese de doutorado em linguística). Yale University, New Haven, Connecticut. Published by Garland Press, New York.

Praça, Walkíria Neiva (2007). Morfossintaxe da língua Tapirapé (Família Tupi-Guarani). (Tese de doutorado em linguística). Brasília, DF: Universidade de Brasília.

Rodrigues, Aryon Dall'Igna (1984-1985). Relações internas na família linguística Tupí-Guaraní. Revista de Antropologia 27/28: 33-53.

Rodrigues, Aryon Dall'Igna; Cabral, Ana Suelly Arruda Câmara (2002). Revendo a classificação da família Tupí-Guaraní. Línguas indígenas brasileiras: Fonologia, gramática e história. Atas do I Encontro Internacional do Grupo de Trabalho sobre Linguas Indigenas da ANPOLL, T.1: 327-337.Belém: Editora EDUFPA. 
Salas, Adalberto (1992). El mapuche o araucano. Madrid: Editorial MAPFRE.

Smith, Carolota (1997). The parameter of aspect (2nd ed.). Dordrecht: Kluwer Academic Publishers.

Solano, Eliete de Jesus Bararuá (2009). Descrição gramatical da língua Araweté (Tese de doutorado em linguística). Brasília, DF: Universidade de Brasília.

Spencer, Andrew (1995). Incorporation in Chukchi. Language 71(3): 439-489.

Vendler, Zeno (1967). Linguistics in phylosophy. Ithaca/London: Cornell University Press.

Verkuyl, Henk (1989). Aspectual classes and aspectual composition. Linguistics and Philosophy 12: 39-43.

Vieira, Márcia Maria Damaso (2010). Os núcleos aplicativos e as línguas indígenas brasileiras. Revista de Estudos da Linguagem 18(1): 141-164.

Recebido: $13 / 4 / 2020$

Versão revista: 5/10/2020

Aceito: $9 / 10 / 2020$

Publicado: 20/10/2020 